\title{
ASPECTOS LEGAIS DA MORTE
}

\author{
LEGAL ASPECTS OF THE DEATH
}

Ricardo Gariba Silva

Docente. Faculdade de Odontologia de Ribeirão Preto - USP. Curso de Odontologia -UNAERP. Doutor em Direito - FHDSS de Franca - UNESP. ricardogariba@yahoo.com.br

Silva RG. Aspectos legais da morte. Medicina (Ribeirão Preto) 2005; 38 (1): 60-62.

Resumo: O presente trabalho pretende esclarecer e realçar os aspectos legais do evento morte para o médico, já que este, por atribuição normativa, e pelas circunstâncias fáticas e práticas, é quem, normalmente, a atesta em documento próprio. São enfocados os efeitos legais e jurídicos da morte, e sua repercussão no mundo do direito, com a importância e correlação que possui com a declaração médica da morte. Ao reavivar os conceitos, pretende-se que o médico esteja cada vez mais consciente do seu ato profissional enfocado no presente trabalho, e que seja, como sempre, diligente e zeloso com esta prática profissional pelas, dentre inúmeras outras coisas, repercussões que dela decorrem.

Descritores: Morte.Aspectos Legais.

\section{INTRODUÇÃO}

A questão da morte, quando analisada à luz do direito, traz uma séria de conseqüências plenamente claras e estabelecidas.

Ocorre que, em circunstâncias normais e rotineiras, referido evento é declarado por algum médico, que, normalmente, não tem pleno conhecimento dos efeitos jurídicos e legais decorrentes do ato profissional que praticou.

Dessa forma, reveste de importância o esclarecimento daqueles militantes da Medicina, já que, ao declararem o processo biológico que pôs fim à vida, trazem com tal prática inúmeras conseqüências que emprestam importância e responsabilidade ainda maiores ao ato que praticam.

O objetivo do presente artigo é o de destacar os aspectos legais do evento morte à luz do direito, e dirigido aos profissionais da Medicina, de modo que estes possam ter pleno conhecimento e apreensão dos efeitos jurídicos dos seus atos profissionais após o encerramento do processo vital, como medida última destinada à pessoa, ressalvados os trabalhos de investigação e estudos post mortem.

\section{DESENVOLVIMENTO}

Por paradoxal que possa parecer, ao abordar os efeitos legais da morte, necessário se faz refletir sobre aqueles relacionados ao início da vida. E tal assertiva se torna mais clara ao entendermos que o evento morte põe fim àquilo que se iniciou e teve repercussões que, no caso presente, refletem no mundo jurídico.

A duração da vida coincide com a da personalidade jurídica, que se constitui em um atributo da pessoa humana, e a ela está indissoluvelmente ligada. Assim, desde que vive e enquanto vive, o homem é dotado de personalidade ${ }^{1}$.

Não obstante a personalidade começar com o nascimento e terminar com a morte ${ }^{2,3,4}$, a ordem jurídica admite a existência da personalidade em hipóte- 
ses em que não ocorre a coincidência citada entre a ela e a vida, por meio de um processo técnico de ficção. O direito admite que a personalidade fictícia, artificial, presumida, exista ao lado daquela denominada real, verdadeira, autêntica ${ }^{5}$. Segundo o autor consultado, os casos em que se verifica a personalidade fictícia são do nascituro, do ausente e da pessoa cuja possibilidade de vir a existir é admitida para a aquisição de direitos.

Assim, ao declarar a morte de uma pessoa, o médico está, mediante esta prática, declarando, também, que houve a extinção da personalidade daquele indivíduo, já que, conforme dito anteriormente, referida extinção é decorrência do evento morte ${ }^{1,2,3,5 / 9}$.

Ao médico compete atestar a ocorrência da morte, em documento solene, o atestado de óbito, que tem como finalidades principais a confirmação da ocorrência do evento, a definição da causa mortis e a satisfação do interesse médico-sanitário, embora tal testemunho possa ser feito por duas testemunhas idôneas, que tenham presenciado ou verificado o falecimento ${ }^{10,11}$. O documento que contém a declaração médica é o atestado de óbito, que se constitui em garantia à família e à sociedade de que não há possibilidades de o indivíduo estar vivo, podendo ser processada legalmente a inumação (França: 2001, p. 329) ${ }^{10}$.

Basta que se examinem as circunstâncias práticas para se constatar a importância do ato médico em comento, já que a declaração da morte por meio de testemunhas é de ocorrência mais rara, sendo o expediente mais comum a emissão pelo profissional dos atestados.

Uma vez emitido o atestado de óbito, estabelecido, formalmente, está o fim da existência humana, bem como da personalidade civil ${ }^{10}$.

Sendo a morte o limite do ciclo vital do homem, o conhecimento do momento em que tal limite foi atingido constitui-se em um problema fundamentalmente médico-legal ${ }^{6}$. E, a partir dele, surgem as suas repercussões no mundo do direito.

Os efeitos jurídicos da morte, na esfera civil, segundo Limongi França (1996: 64) ${ }^{6}$, são a dissolução da comunhão de bens entre cônjuges, da sociedade conjugal, do pátrio poder (atualmente entendido como poder familiar), extinção do dever de alimentos, do usufruto, dentre outros. Porém, o efeito civil de grande repercussão, ou seja, a abertura da sucessão do falecido, além de outros como o legado de usufruto, sem fixação de tempo, que perdura até a morte do legatário; a morte do herdeiro livra os bens vinculados da cláusula de inalienabilidade e semelhantes; a morte do fiduciário gera a consolidação do fideicomisso. $\mathrm{Na}$ seara penal, o autor aponta a extinção da punibilidade do criminoso com a morte deste, bem como a suspensão da instância dos efeitos processuais.

Merece destaque o fato de que a morte, embora determine a extinção da personalidade natural, não impede que determinados atos do falecido ultrapassem-na, com efeitos legais previstos. É o que ocorre, por exemplo, nos casos em que o morto se faz presente no mundo dos vivos mediante a permanência da sua vontade expressada por meio de testamento. Ainda mais, tem o morto direito à revisão criminal, com o fito de absolvição, e, também, pode ser declarada a sua falência ${ }^{6}$.

Não obstante os direitos do morto acima apontados, Diniz (2002: 201) $)^{2}$ ressalta o respeito que é devido ao cadáver, bem como o direito à imagem e à honra do falecido, que deve ser protegido por aqueles legitimados para exercer tal tutela. Aponta a autora, ainda, a possibilidade de ocorrência de promoção de militares e de servidores públicos post mortem.

\section{CONSIDERAÇÕES FINAIS}

A ocorrência da morte e a declaração deste fato, na maioria dos casos, se dão mediante o acompanhamento médico, senão em casos da evolução de doença, mas pela declaração da sua ocorrência mediante atestado de óbito.

Evidente se faz, pois, a presença do médico em virtude de tudo o exposto, e, da mesma, forma, a importância dos seus atos profissionais na declaração do evento morte. E, uma vez declarado o fim do processo biológico vital, segundo os critérios profissionais médicos, surgem, no campo do direito, os efeitos anteriormente enumerados com o intuito de realçar as decorrências jurídicas do ato praticado que, nem sempre, os profissionais da saúde têm ciência deles.

Reveste-se de importância, pois, o realce das decorrências jurídicas da morte, e a inserção do médico no início de todo este processo, para que o profissional da saúde tenha, ainda mais, ciência e consciência das repercussões do seu ato profissional de declaração do evento morte e da sua importância em todo o sistema jurídico, para que, também neste ato, o médico, com a mesma diligência, critério, e dedicação que são peculiares a estes profissionais, possa atuar de modo a refletir a verdade dos fatos. 
Normalmente, por mais paradoxal que seja, o fim da vida, do qual decorrem emoções tristes, pode representar o início de batalhas jurídicas, que provocarão emoções igualmente ruins.

$\mathrm{E}$, às vezes, o ato médico em comento, que está diretamente ligado às primeiras emoções, pode se ligar às demais, por longo tempo, se não refletir a realidade dos fatos. Nestas hipóteses, os atos profissionais médicos prolongam-se para bem depois da morte do indivíduo, ou podem determinar, de plano, o fim da reivindicação de alguns direitos.

Dessa forma, por estarem diretamente ligados ao fim da personalidade natural é que os atos médicos de declaração da morte são, da mesma forma, importantes como os demais atos de preservação da vida. São enfoques e fins diferentes, cada qual importante em cada momento em que são praticados: a preservação da vida, e a declaração da morte.

Silva RG. Legal aspects of the death. Medicina (Ribeirão Preto) 2005; 38 (1): 60-62.

Abstract: The present work intends to clarify and to enhance the legal aspects of the death for the physician. Physicians, as a result of normative attribution, and of the practical circumstances, normally, certify the death in proper document. The legal consequences of the death are focused, with its importance and correlation with the medical declaration of the death. The physician must be more conscientious of his professional act, and, therefore, be more diligent and always zealous with his practices, because of its effects.

Keywords: Death. Legal Aspects.

\section{REFERÊNCIAS BIBLIOGRÁFICAS}

1 - Pereira CMS. Instituições de direito civil. 18 ed. Rio de Janeiro: Forense; 1997. Vol. 1. p. 148-50.

2 - Diniz MH. Curso de direito civil brasileiro. 18 ed. atualizada de acordo com o novo código civil. São Paulo: Saraiva; 2002. Vol. 1, p. 197-201.

3 - Wald A. Direito civil. Introdução e parte geral. 9 ed. São Paulo: Saraiva; 2002. p. 117-20.

4 - Rodrigues S. Direito civil. Parte geral. 34 ed. São Paulo: Saraiva; 2003. Vol. 1, p. 35-8.

5 - Gomes O. Introdução ao direito civil. 18 ed. Rio de Janeiro: Forense; 2001. p. 143-4.

6 - Limongi França R. Instituições de direito civil. 4 ed. atualizada. São Paulo: Saraiva; 1996. p. 61-4.
7 - Miranda, Pontes de. Tratado de direito privado. Parte geral. Tomo I. 1 ed. Campinas: Bookseller, 1999. p. 282-97.

8 - Gagliano OS, Pamplona Filho R. Novo curso de direito civil. Parte geral. São Paulo: Saraiva; 2002. Vol. !, p. 132-41.

9 - Monteiro WB. Curso de direito civil. Parte geral. 39 ed. São Paulo: Saraiva; 2003. p. 77-81.

10 - França GV. Medicina legal. 6 ed. Rio de Janeiro: Guanabara-Koogan; 2001. 580 p.

11 - Venosa SS. Direito civil. Parte geral. 4 ed. São Paulo: Atlas, 2004. Vol. 1,p.191-200. 